\title{
Relationship Between MRONJ (Medication Related Osteonecrosis of the Jaw) and Endodontic Theraphy
}

ISSN: 2637-7764

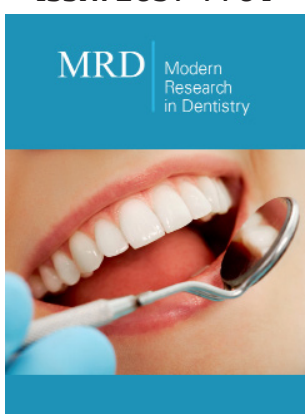

*Corresponding author: Picardo Silvana Noemi, Head of Practical Works Chair in Oral and Maxillofacial Surgery II School of Dentistry University of Buenos Aires and Department of Dentistry Favaloro Foundation University Hospital

Submission:

Published: 此 September 29, 2020

Volume 5 - Issue 4

How to cite this article: Picardo Silvana Noemi, Rodriguez Genta Sergio, Basilaki Jorge Mario, Lopreite Gustavo Horacio, Rey Eduardo. Relationship Between MRONJ (Medication Related Osteonecrosis of the Jaw) and Endodontic Theraphy. Mod Res Dent. 5(4). MRD. 000618. 2020.

DOI: 10.31031/MRD.2020.05.000618

Copyright@ Picardo Silvana Noemi, This article is distributed under the terms of the Creative Commons Attribution 4.0 International License, which permits unrestricted use and redistribution provided that the original author and source are credited.
Picardo Silvana Noemi ${ }^{1 *}$, Rodriguez Genta Sergio ${ }^{2}$, Basilaki Jorge Mario ${ }^{3}$, Lopreite Gustavo Horacio ${ }^{4}$, Rey Eduardo ${ }^{5}$

${ }^{1}$ Head of Practical Works Chair in Oral and Maxillofacial Surgery II School of Dentistry University of Buenos Aires and Department of Dentistry Favaloro Foundation University Hospital, Argentina

${ }^{2}$ Head of Practical Works Chair in Oral and Maxillofacial Surgery II School of Dentistry, University of Buenos Aires, Argentina

${ }^{3}$ Professor of Endodontics Kennedy University School of Dentistry, Former Associate professor of endodontics at the Buenos Aires School of Dentistry, Licensed teacher of the School of Dentistry of the University of Buenos Aires, Vocal Incoming President of the Sociedad De Endodoncia, Argentina

${ }^{4}$ Associate Professor of Endodontics Kennedy University School of Dentistry, Former Associate professor of endodontics at the Buenos Aires School of Dentistry, Licensed teacher of the School of Dentistry of the University of Buenos Aires, Former President of the Sociedad De Endodoncia, Argentina

${ }^{5}$ President of the National Academy of Dentistry, Consultant to the National Academy of Medicine, Former Professor of Oral and Maxillofacial Surgery School of Dentistry, University of Buenos Aires, Argentina

\section{Abstract}

The American Surgery of Bone Mineral Research (ASBMR) in 2007 defined MRONJ as "necrotic bone area exposed to the oral environment with more than eight weeks of permanence, in the presence of chronic treatment with BPs, in the absence of radiation therapy to the head and neck". In 2014 the American Association of Oral and Maxillofacial Surgeons (AAOMS) divided the MRONJ into 4 stages from 0 to 3, according to the clinical and radiological aspect of the osteonecrotic lesion:
A. stage 0: Osteonecrotic lesion without sign-pathognomonic evidence of osteonecrosis.
B. stage 1: osteonecrotic lesion with clinical signs and absence of clinical symptoms.
C. Stage 2: Osteonecrotic lesion with sign and evident clinical symptoms.
D. Stage 3: Osteonecrotic lesion with signs and evident symptoms that involve noble structures: pathological fractures, anesthesia of the lower dental nerve, oral-nasal communication, oral-sinus communication, skin fistulas. This article proposes explain relationship between MRONJ and endodontic therapy [1].

Keywords: Osteonecrotic lesion; Dental nerve; Oral-nasal; Endodontic; Bone accumulation; Pathology

Abbreviations: AR: Antiresorptive; BPs: Bisphosphonates; DS: Denosumab; AD: Antiangiogenic Drugs, MRONJ: Medication Related Osteonecrosis of the Jaw; ET: Endodontic Therapy

\section{Introduction}

Antiresorptives (AR): Bisphosphonates (BP), Denosumab (DS) and Antiangiogenic drugs are physician indication in low in cases of Osteoporosis, Paget's Disease, Imperfect Osteogenesis and Fibrous Dysplasia and high concentration to treat Hypercalcemia associated with oncology patients [2]. 
It is clear from the suggested treatments that before the diagnosis of MRONJ the therapeutic attitude is consolidated in non-invasive maneuvers as endodontic therapy regarding the manipulation of bone tissue, performing the pertinent clinical controls in order to avoid systemic spread to deep planes, due to its pharmacokinetics of bone accumulation that could condition a septicemia picture in affected patients, interacting with the attending physician in the event of a certain event of exacerbation of injuries that affect the patient's general health [3].

Endodontic therapy requires adequate knowledge of the anatomy of the root canal system and its multiple variations [4-7], of the biology and pathology of the dental pulp and periradicular tissues [8]. In turn, the operative procedures require proper disinfection and chemical-mechanical preparation of the root canal, its cleaning and shaping [9-12], and its obturation by means of biocompatible materials that have the ability to stimulate the reparative process [13-15] Tissue repair is an essential process that restores tissue integrity and regular function. However, different therapeutic factors and clinical conditions can interfere in this periapical healing process [16]. This procedure pretends minimize bone injuries in incipient stages MRONJ. It is known respective surgeries are required in case MRONJ stage 3 are consolidated and non-invasive maneuvers could not be effective [1].

\section{Conclusion}

At present, a large part of the endodontic treatments performed in the clinic are due to pathologies that refer to the pulp and the periapic. The pulp is a richly vascularized and innervated tissue, delimited by an inextensible environment such as dentin, with terminal blood circulation and a small caliber periapic circulatory access zone. All this means that the defensive capacity of the pulp tissue is very limited against the various aggressions that it may suffer. The pulp tissue can also be affected by a retrograde infection [17], from the periodontal ligament or from the apex during a periodontitis process. Because periapical pathology almost always precedes pulp involvement.

Due to the various causes that produce pulp and periapical pathology, the basic pathogenic process that develops is that of the inflammatory response. The pulp will react causing pulpitis, an inflammation that occurs in response to direct and immune mechanisms. The direct mechanisms are microorganisms, the results reach the pulp through the exposed dentin tubules, either by caries, trauma or irritating factors (bacterial products, bacterias, endotoxins, etc.), which when penetrating through the tubules dentinals, destroy the odontoblast and underlying cells [18]. Complement factors and immunoglobulins act on immune mechanisms.

Endodontic therapy would be providing greater dental therapeutic benefit to compensate for the morbidity of the pathology MRONJ. There is a need not to suspend antiresorptive medication necessary according to medical criteria both in osteoporotic and oncological patients, since in that sense, according to the pharmacokinetics and pharmacodynamics of AR drugs $[19,20]$.

\section{References}

1. Ruggiero S, Saxena D, Tetradis S, Aghaloo T, Ioannidou E (2018) Task force on design and analysis in oral health research: medication-related osteonecrosis of the jaw. JDR Clin Trans Res 3(3): 222-225.

2. Ruggiero SL, Dodson TB, Fantasia J, Goodday R, Aghaloo T, et al. (2014) American association of oral and maxillofacial surgeons position paper on medication-related osteonecrosis of the jaw. J Oral Maxillofac Surg 72(10): 1938-1956

3. Picardo SN, Rey EA (2017) Clinical healthcare protocol for bisphosphonate related osteonecrosis of the jaw. International Journal of Dentistry and Oral Health 3: 20-22.

4. Mărgărit R, Andrei OC, Mercuţ V (2012) Anatomical variation of mandibular second molar and its implications in endodontic treatment. Rom J Morphol Embryol 53(2): 413-416.

5. Jang YE, Kim Y, Kim B, Kim SY, Kim HJ (2019) Frequency of non-single canals in mandibular premolars and correlations with other anatomical variants: an in vivo cone beam computed tomography study. BMC Oral Health 19(1): 272.

6. Raisingani D, Gupta S, Mital P, Khullar P (2014) Anatomic and diagnostic challenges of C-shaped root canal system. Int J Clin Pediatr Dent 7(1): 35-39.

7. Theruvil R, Ganesh C, George AC (2014) Endodontic management of a maxillary first and second premolar with three canals. J Conserv Dent 17(1): 88-91.

8. López Marcos JF (2004) Aetiology, classification and pathogenesis of pulp and periapical disease. Med Oral Patol Oral Cir Bucal 9 Suppl: 5857.

9. Kuzekanani M, Walsh LJ, Yousefi MA (2009) Cleaning and shaping curved root canals: Mtwo vs ProTaper instruments, a lab comparison. Indian J Dent Res 20(3): 268-270.

10. Siddique R, Nivedhitha MS (2019) Effectiveness of rotary and reciprocating systems on microbial reduction: A systematic review. J Conserv Dent 22(2): 114-122.

11. Koçak MM, Koçak S, Türker SA, Sağlam BC (2016) Cleaning efficacy of reciprocal and rotary systems in the removal of root canal filling material. J Conserv Dent 19(2): 184-188.

12. Walia V, Goswami M, Mishra S, Walia N, Sahay D (2019) Comparative evaluation of the efficacy of chlorhexidine, sodium hypochlorite, the diode laser and saline in reducing the microbial count in primary teeth root canals-an In vivo study. J Lasers Med Sci 10(4): 268-274.

13. Farias AB, Pereira KF, Beraldo DZ, Yoshinari FM, Arashiro FN (2016) Efficacy of three thermoplastic obturation techniques in filling ovalshaped root canals. Acta Odontol Latinoam 29(1):76-81.

14. Lone MM, Khan FR (2018) Evaluation of micro leakage of root canals filled with different obturation techniques: An In Vitro Study. J Ayub Med Coll Abbottabad 30(1): 35-39.

15. Huang Y, Celikten B, de Faria Vasconcelos K, Pinheiro Nicolielo LF, Lippiatt N, et al. (2017) Micro-CT and nano-CT analysis of filling quality of three different endodontic sealers. Dentomaxillofac Radiol 46(8): 20170223.

16. Holland R, Gomes JE Filho, Cintra LTA, Queiroz ÍOA, Estrela C (2017) Factors affecting the periapical healing process of endodontically treated teeth. J Appl Oral Sci 25(5): 465-476.

17. Walton RE, Torabinejad M (1996) Principles and practice of endodontics. WB Saunders (Ed.), Philadelphia, Pennsylvania, USA, p. 16. 
18. Simon J (1999) Patología periapical. In: Cohen S, Burns R (Eds.), Vías de la pulpa, Harcourt-Mosby, Madrid, Spain, pp. 410-438.

19. Khan AA, Morrison A, Kendler DL, Rizzoli R, Hanley DA, et al. (2017) Case-based review of Osteonecrosis of the Jaw (ONJ) and application of the international recommendations for management from the international task force on ONJ. J Clin Densitom 20(1): 8-24.

20. Fleisher KE, Kontio R, Otto S (2016) Antiresortive drug-related ostenecrosis of the jaw (ARONJ)-a guide to research. Switzerland, p. 64. 